\title{
Rapid response seismic networks in Europe: lessons learnt from the L'Aquila earthquake emergency
}

\author{
Lucia Margheriti $^{1, \star}$, Lauro Chiaraluce ${ }^{1}$, Christophe Voisin ${ }^{4}$, Giovanna Cultrera ${ }^{2}$, Aladino Govoni ${ }^{1,11}$,
} Milena Moretti ${ }^{1}$, Paola Bordoni ${ }^{1}$, Lucia Luzi ${ }^{3}$, Riccardo Azzara ${ }^{2}$, Luisa Valoroso ${ }^{1}$, Raffaele Di Stefano ${ }^{1}$, Armand Mariscal ${ }^{4}$, Luigi Improta ${ }^{2}$, Francesca Pacor ${ }^{3}$, Giuliano Milana ${ }^{2}$, Marco Mucciarelli ${ }^{5}$, Stefano Parolai ${ }^{6}$, Alessandro Amato ${ }^{1}$, Claudio Chiarabba ${ }^{1}$, Pasquale De Gori ${ }^{1}$, Francesco P. Lucente ${ }^{1}$, Massimo Di Bona ${ }^{1}$, Maurizio Pignone ${ }^{1}$, Gianpaolo Cecere ${ }^{1}$, Fabio Criscuoli ${ }^{1}$, Alberto Delladio ${ }^{1}$, Valentino Lauciani ${ }^{1}$, Salvatore Mazza ${ }^{1}$, Giuseppe Di Giulio ${ }^{2}$, Fabrizio Cara ${ }^{2}$, Paolo Augliera ${ }^{3}$, Marco Massa $^{3}$, Ezio D'Alema ${ }^{1}$, Simone Marzorati ${ }^{1}$, Monika Sobiesiak ${ }^{6,12}$, Angelo Strollo ${ }^{6}$, Anne-Marie Duval $^{7}$, Pascal Dominique ${ }^{8}$, Bertrand Delouis ${ }^{9}$, Anne Paul ${ }^{4}$, Stephan Husen ${ }^{10}$, Giulio Selvaggi ${ }^{1}$

1 Istituto Nazionale di Geofisica e Vulcanologia, Centro Nazionale Terremoti, Rome, Italy

2 Istituto Nazionale di Geofisica e Vulcanologia, Sezione Roma 1, Rome, Italy

3 Istituto Nazionale di Geofisica e Vulcanologia, Sezione Milano-Pavia, Milan, Italy

4 Université de Grenoble, Institut des Sciences de la Terre, Laboratoire de Géophysique Interne et Tectonophysique, Grenoble, France

5 Università della Basilicata, Dipartimento di Strutture, Geotecnica, Geologia Applicata all'Ingegneria, Potenza, Italy

6 Helmholtz-Zentrum Potsdam - Deutsches GeoForschungsZentrum GFZ, Potsdam, Germany

7 CETE Méditerranée (Centre d'Etudes Techniques de l'Equipement), Laboratoire régional des ponts et chaussées, Nice, France

8 BRGM (Bureau de Recherche Géologiques et Minières), Service Aménagement et Risques Naturels, Orléans, France

9 Université de Nice-Sophia Antipolis, Institut Geosciences AZUR, Valbonne - Sophia Antipolis, France

10 ETH Zürich (Eidgenössische Technische Hochschule Zürich), Zurich, Switzerland

11 Istituto Nazionale di Oceanografia e Geofisica Sperimentale - OGS, Sgonico (Trieste), Italy

12 Christian-Albrechts-Universität zu Kiel, Institut für Geowissenschaften, Kiel, Germany

\section{Article history}

Received January 20, 2011; accepted June 14, 2011.

Subject classification:

Surveys, measurements and monitoring, Tectonics, Instruments and techniques, Rapid response seismic networks, Open data archives.

\section{ABSTRACT}

The largest dataset ever recorded during a normal fault seismic sequence was acquired during the 2009 seismic emergency triggered by the damaging earthquake in L'Aquila (Italy). This was possible through the coordination of different rapid-response seismic networks in Italy, France and Germany. A seismic network of more than 60 stations recorded up to 70,000 earthquakes. Here, we describe the different open-data archives where it is possible to find this unique set of data for studies related to hazard, seismotectonics and earthquake physics. Moreover, we briefly describe some immediate and direct applications of emergency seismic networks. At the same time, we note the absence of communication platforms between the different European networks. Rapid-response networks need to agree on common strategies for network operations. Hopefully, over the next few years, the European Rapid-Response Seismic Network will became a reality.

\section{Introduction}

The rapid deployment of temporary seismic stations soon after the occurrence of a moderate-to-large earthquake is an essential action. This serves both to upgrade the resolution of the permanent monitoring systems of the ongoing seismic crisis, and to ensure the availability of high quality scientific datasets for studies related to hazard, seismotectonics and earthquake physics. Moreover, temporary improvement of the detection capabilities of local and regional networks during periods of special interest, such as for foreshock/aftershock sequences and for unusual background, swarm or induced seismicity, is becoming a major aim for the whole of the seismological community.

The near-real-time availability of high-quality datasets recorded by rapid-response temporary networks also 


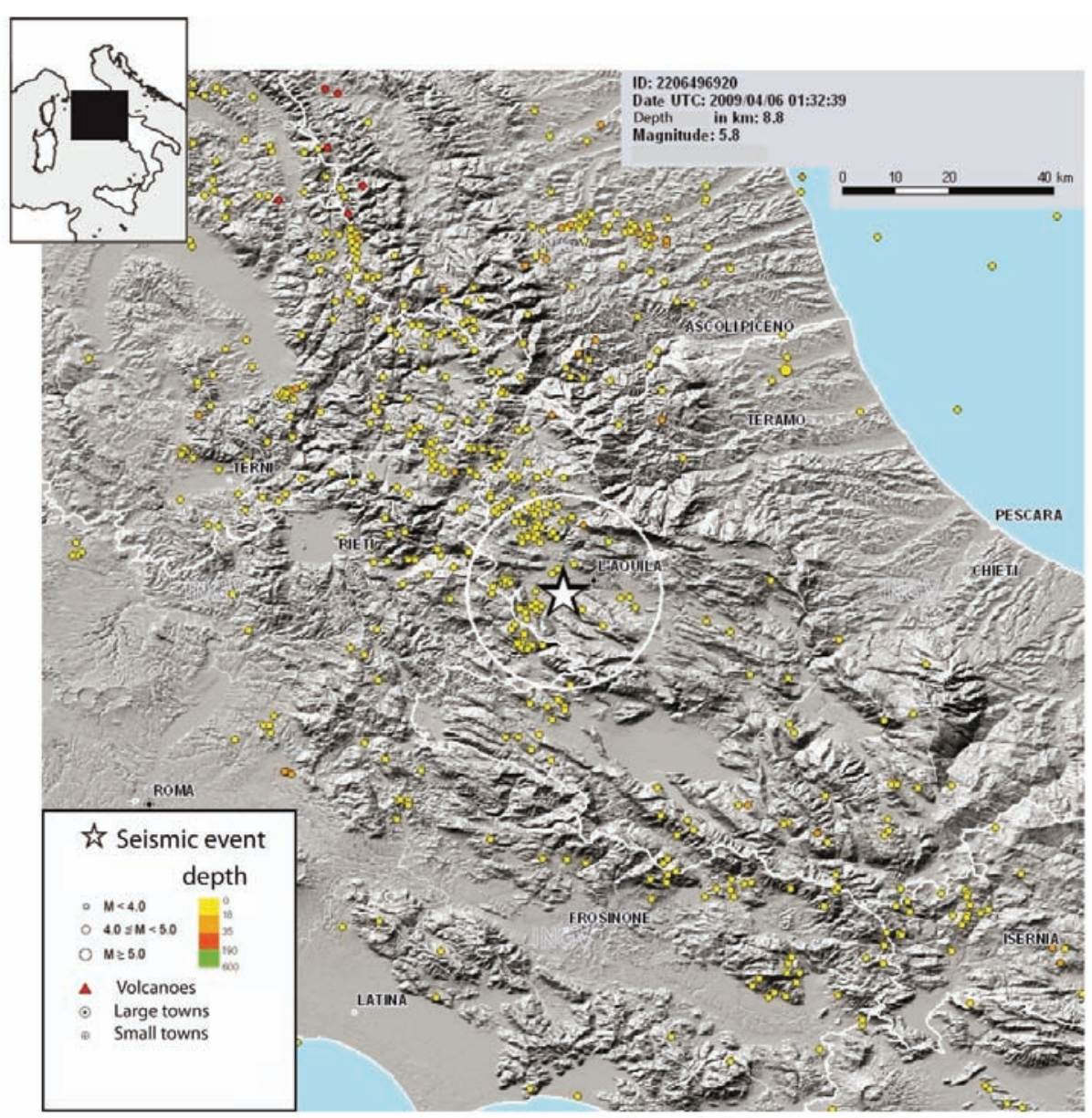

Figure 1. Location of the earthquake that occurred near L'Aquila on April 6, 2009, at 01:32 UTM. The map shows the instrumental seismicity of the INGV Italian Seismic Bulletin (from January 1, 2003, to December 31, 2008, with $M \geq 2.5$ ).

provides a crucial source of information for decision makers to evaluate and update the existing situations, and for the support of emergency management during seismic crises.

In Europe, the temporary deployment of local seismic networks is mainly a national task, and it is generally managed by some of the major public research Institutions. The networking of the existing capabilities throughout Europe would improve the ability for rapid and more efficient response networks to support the emergency management, with a valuable impact on hazard mitigation.

An example of spontaneous and collaborative rapidresponse seismic network coordination in a European framework was triggered by the occurrence of the disastrous L'Aquila earthquake (central Italy) in April 2009, when groups from different European institutions installed dense local networks to record the aftershock sequences [Chiaraluce et al. 2011].

In this report, we will overview this experience, to highlight the positive aspects, and those that require further effort to optimize the outcomes, in terms of coordination between the European seismological communities.

\section{The L'Aquila earthquake emergency}

On April 6, 2009, at 03:32 local time, a shock with a moment magnitude greater than $6(\mathrm{Mw}=6.1$, Scognamiglio et al. 2010; $\mathrm{Mw}=6.3$, Pondrelli et al. 2010) woke up millions of people in central Italy, including many in Rome and in many other towns from the Tyrrhenian to the Adriatic coast, and through the regions of Abruzzo, Lazio, Umbria, Marche and Molise. The town of L'Aquila and its $\sim 70,000$ inhabitants were sleeping right above the fault that ruptured that night. More than half of the buildings in down-town L'Aquila were severely damaged, and many collapsed; more than 300 people died under the ruins. The artistic, historic and cultural heritage of this beautiful area disappeared in a handful of seconds.

Using the data collected by the seismic and geodetic monitoring systems in Italy [Amato and Mele 2008] that are managed by the Istituto Nazionale di Geofisica e Vulcanologia (INGV) and funded by the Italian National Civil Protection (DPC), the main parameters of this earthquake were immediately evaluated and made available to the scientific and civil community (web page http://iside.rm.ingv.it/iside/standard/index.jsp).

The permanent seismic stations in the region (RSN and Mednet) had a mean inter-station distance of $30 \mathrm{~km}$. To improve the monitoring resolution of these seismic and geodetic networks, several Italian teams moved into the epicentral area to install temporary monitoring networks only a few hours after the mainshock occurred. Two groups, Rete Mobile INGV-CNT (Centro Nazionale Terremoti; 
National Earthquake Center) Roma (Re.Mo), and Rete Mobile Telelemetrata from the INGV-CNT Grottaminarda (ReMoTel), had already started the installation on the morning of April 6, 2009: by the end of that day, eight standalone and three real-time stations were operating, which reduced the mean inter-station distance to about $20 \mathrm{~km}$. The new geometry of the network was defined to optimize the seismic network coverage while taking into account the main cultural noise sources and the land topography. In less than $30 \mathrm{~h}$ from the mainshock, the French seismic crisis committee had made 20 seismic stations available to the INGV. Then four scientists from the Laboratoire de Géophysique Interne et Tectonophysique (LGIT) of Grenoble moved from France to arrive in L'Aquila on the evening of April 7, 2009. After a coordination meeting with the INGV-CNT personnel, starting on April 8, 2009, all of the 20 stations were deployed in four days through this spontaneous Italian-French teamwork. By this time, the spacing between stations had decreased to below $10 \mathrm{~km}$ (two stations were also installed by INGV-Catania [CT] as part of Re.Mo); the configuration of the network, devoted to earthquake location was fixed from April 12 to June 26, 2009.

The day after the mainshock (April 7, 2009), other groups started installing stations to detect site effects and building responses; the Institutions involved in this activity included: the INGV (Milano-Pavia [MI-PV]; Sismologia e Tettonofisica, Roma1; Centro Nazionale Terremoti [CNT]; Osservatorio d'Arezzo), Helmholtz Zentrum Potsdam (GeoForschungs-Zentrum [GFZ]), Università della Basilicata and two French groups (LRPC de Nice, Centre d'Etudes Techniques de l'Equipement Mediterranée [CETE], and the Bureau de Recherches Géologiques et Minières [BRGM]).

By April 12, 2009, the deployment in the epicentral area (Figure 2; Table 1) included a total of 61 stand-alone seismic stations (23 of which were devoted to site and building responses) and nine seismic stations connected in real time to the monitoring room in Rome and integrated into the INGV National Seismic Network (Figure 2; Table 1).

The contacts between the different groups did not follow any pre-defined communication channels or procedures. This aspect resulted in the need for several operational meetings, which slowed down the initial process of station deployment. It was decided that each group (Italian, French and German) had to take care of the initial deployment of their stations, while the maintenance was mainly a joint and coordinated effort. In this way we were able to optimize the use of the stations, to accomplish the different tasks necessary.

In the following months, the network geometry was reorganized according to different needs. Stations devoted to site response investigations were moved to areas of particular interest for the Civil Protection, to collect data that would be useful for seismic microzonation studies [Cultrera et al.
2011]. Stations devoted to earthquake location were reorganized according to their availability, to better follow the temporal and spatial evolution of the seismic sequence [Margheriti et al. 2010]. Some of the real-time stations operated until the end of 2010.

\section{The data archives}

The team (INGV-CNT and LGIT) that was running the networks that were mainly devoted to earthquake detection and location decided that it was important to share the continuous recordings. To achieve this aim, the common SEED (Standard for the Exchange of Earthquake Data) data format was chosen. The continuous data recorded by the 21 mobile stations operated by the INGV-CNT that were deployed during the L'Aquila sequence (Re.Mo networkRM01 to RM32 stations IV network) were checked and converted to the SEED data format, and then made available to the scientific community using the EIDA platform (European Integrated Data Archive, http:/ / eida.rm.ingv.it/). All of the metadata available was also checked and converted to the SEED format. These datasets spanned from a few hours after the April 6, 2009, mainshock (first data recorded at 04:43:08 UTC) to March 23, 2010, when the last nine stations of Re.Mo were closed, and they consist of some 270 GB of data. A total of 30 sites where occupied during this period, with the network geometry adapted to the evolution of the seismic sequence. The data recorded by the 20 seismic stations installed by LGIT (Grenoble, France) between April and June 2009 were distributed in the same SEED format (at http://www.fosfore.ipgp.fr/en/ in "Fosfore Portal" under "Stations", network XJ), together with the metadata.

The EIDA archive also provides access to the National Seismic Network data, including the Re.Mo.Tel stations that were deployed after the mainshock and received in real time (T0101 to T0110 stations IV network). Some of these stations operated until the end of 2010, and they contributed to the real-time hypocentral locations for many hundreds of local and regional earthquakes, thus significantly lowering the detection threshold of the National Seismic Network in the region.

All of the other data that were recorded to evaluate site effects and to monitor building structures have been archived by their reference Institutions. A set of events with magnitudes greater than 3 is now shared by all participants, and some of these waveforms are archived inside ITACA http:/ /itaca.mi.ingvit/, the Italian accelerometric archive.

Further steps should be followed to build upon the automatic procedures, to rapidly have all of the data in the same format and in the same archive.

\section{Direct applications of the rapid-response networks}

This large amount of data collected is very valuable for scientific studies related to hazard, seismotectonics and 


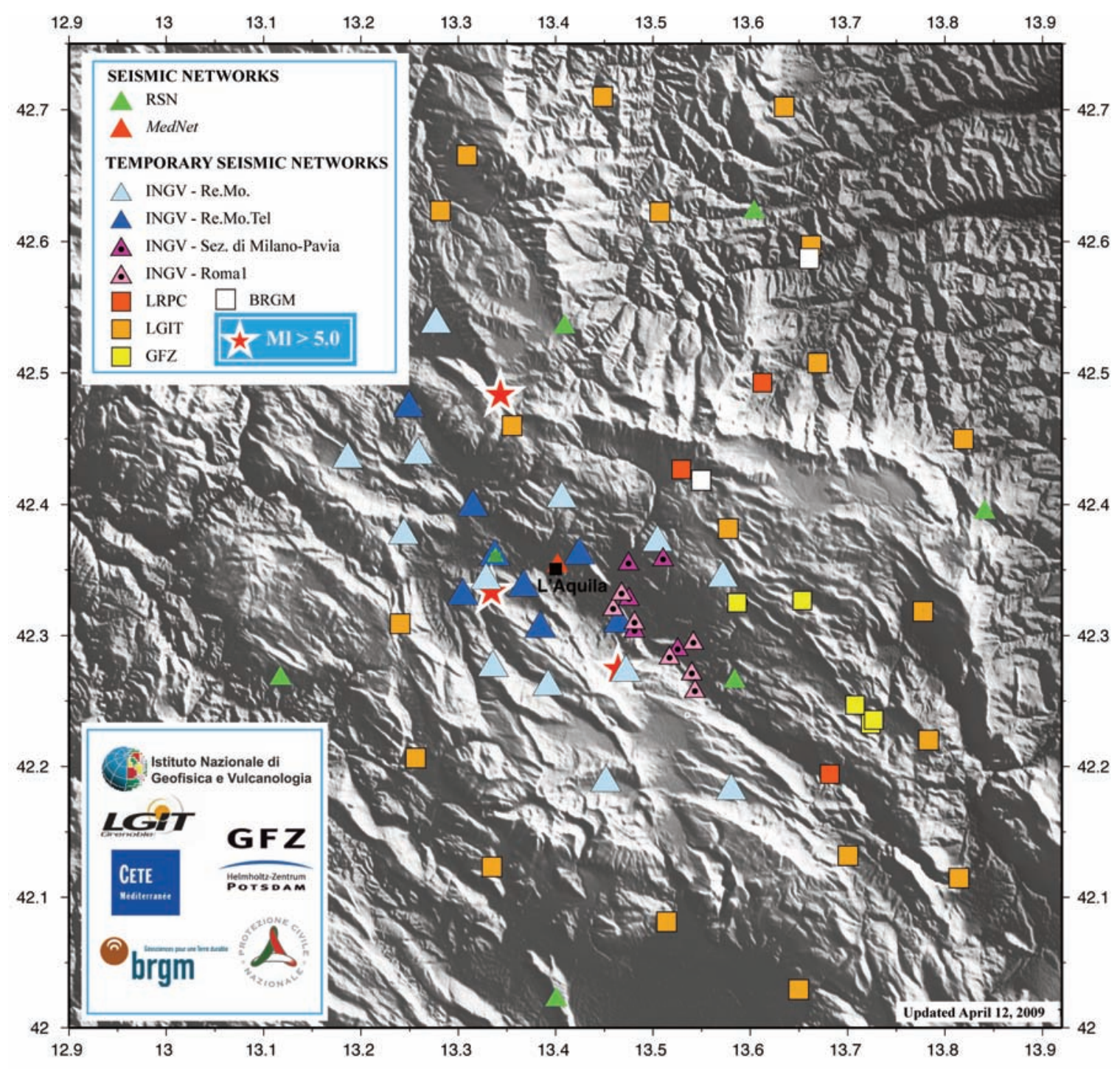

Figure 2. Deployment of the seismic stations during the L'Aquila April 2009 seismic sequence. Several European rapid-response seismic networks took part in the deployment.

\begin{tabular}{|c|c|c|c|c|c|c|}
\hline Institute & Network name & $\begin{array}{l}\text { Number of } \\
\text { stations }\end{array}$ & $\begin{array}{l}\text { Sta. } \\
\text { name }\end{array}$ & Recording mode & Main aims of the stations & Data availability \\
\hline INGV-CNT & Re.Mo.Tel./IV & 9 & $\begin{array}{l}\text { T0101 } \\
\text { T0110 }\end{array}$ & Real time & Improved detection capacity & $\begin{array}{l}\text { Eida (continuous } \\
\text { recordings) }\end{array}$ \\
\hline INGV CNT-CT & Re.Mo/IV & 21 & $\begin{array}{l}\text { RM01 } \\
\text { RM32 }\end{array}$ & Stand alone & $\begin{array}{l}\text { Seismotectonics and } \\
\text { earthquake physics }\end{array}$ & $\begin{array}{l}\text { Eida (continuous } \\
\text { recordings) }\end{array}$ \\
\hline LGIT & $/ \mathrm{XJ}$ & 20 & $\begin{array}{l}\text { LG01 } \\
\text { LG20 }\end{array}$ & Standalone & $\begin{array}{l}\text { Seismotectonics and } \\
\text { earthquake physics }\end{array}$ & $\begin{array}{l}\text { Fosfore (continuous } \\
\text { recordings) }\end{array}$ \\
\hline BRGM & & 2 & & Stand alone & $\begin{array}{l}\text { Seismotectonics and } \\
\text { earthquake physics }\end{array}$ & Itaca (main events) \\
\hline NICE & & 3 & & Stand alone & Site effects & Itaca (main events) \\
\hline INGV MI & RAIS/IV & 5 & & Stand alone & Site effects & Itaca (main events) \\
\hline GFZ & & 5 & & Stand alone & $\begin{array}{l}\text { Monitoring building } \\
\text { structures }\end{array}$ & Itaca (main events) \\
\hline INGV RM1-AR & & 7 & & Stand alone & Site effects & Itaca (main events) \\
\hline
\end{tabular}

Table 1. Temporary stations deployed in the epicentral area. For abbreviations, see main text. 
earthquake physics. Several studies have already been carried out with the collected data, both for seismotectonic purposes [Chiarabba et al. 2009, Di Stefano et al. 2010, Chiaraluce et al. 2011] and for site effect evaluations [Mucciarelli et al. 2009, D'Alema et al. 2010, Picozzi et al. 2010, Ameri et al. 2011, Bergamaschi et al. 2011, Bordoni et al. 2011, Di Giulio et al. 2011, Milana et al. 2011, Puglia et al. 2011]. Here, we report on two direct applications of the dataset, which helped the decision makers to assess the current situation during the seismic sequence, in terms of indicating villages and towns where checks on building vulnerabilities were urgent, and orienting the definition of the areas for reconstruction.

\subsection{Earthquake location improvements}

The deployment of emergency networks during seismic crises temporarily improves the detection capacity of local and regional networks, through lowering the detectable magnitude threshold. The deployment of the Re.Mo. Re.Mo.Tel. and LGIT networks allowed us to detect all of the earthquakes with a magnitude $M_{L}>0.7$ for the time period from April to June 2009 [Valoroso et al. 2011]. Moreover, these networks made the hypocentral location approximations more precise. This general improvement in the location parameters is illustrated in Figure 3, which shows a map with earthquakes of $M>1.9$ and their location parameters using only the national network (Figure 3a), and combined with the emergency networks (Figure $3 \mathrm{~b}$ ). The residuals for both the arrival times and the location errors halved when the emergency network data were considered (Figure 4).

\subsection{Microzonation}

The data collected for site-response purposes were used for microzonation studies in the months following the mainshock [Gruppo di Lavoro MS_AQ 2010]. Site-responserelated parameters were estimated, such as the fundamental resonance frequencies (fo; Figure 5), calculated as the first peak in the earthquake and noise spectral ratios (http://www.protezionecivile.gov.it/docs/www.ulpiano11. com/docs/microzonazione_pdf/Macroarea1/M1_Milana RumoreStrumentaleMacro1.pdf), and the amplification factors $(\mathrm{Fa})$. The $\mathrm{Fa}$ is here defined as the ratio of the integral of the earthquake response spectra between a soft site and a reference rock site, evaluated in two frequency ranges $(0.5$ $\mathrm{Hz}<\mathrm{f}<2 \mathrm{~Hz}$ and $2 \mathrm{~Hz}<\mathrm{f}<10 \mathrm{~Hz}$ ). These fo and $\mathrm{Fa}$ parameters promoted the easy and fast mapping of the zones that showed different seismic responses. Furthermore, the resonance frequency information helped to constrain the thickness of the soft sediments in the geological model used for the one-dimensional simulations of ground motion that were carried out to estimate the theoretical Fa after calibration with the observed amplification factors ( $\mathrm{Fa}$ ) [Gruppo di Lavoro MS_AQ 2010].

\section{Towards a coordinated European Rapid Response Seismic Network}

The experiences gained during this emergency that arose following the L'Aquila 2009 earthquake emphasized the necessity to define the communication platforms that are needed to facilitate rapid information exchange among the European rapid-response network community.

Some efforts to join forces and to establish contacts had already been carried out in the framework of the ORFEUS Working Group on mobile seismology (http: / www.orfeuseu.org/WorkingGroups/WG3/mobile-stations-summaryonshore.html), within which several European nations are participating: Austria, Czech Republic, Denmark, Finland, France, Germany, Great Britain, Greece, Ireland, Italy, The Netherlands, Norway, Portugal, The Slovak Republic, Spain, Sweden and Switzerland.

A further plan of activities for rapid-response-network coordination is included in the NERA project (Network of European Research Infrastructures for Earthquake Risk Assessment and Migitation) that was approved by the EEC funding scheme: Combination of Collaborative Projects and Coordination and Support Actions for Integrating Activities (CP-CSA); this started in November 2010.

In this framework Italy, Germany, Switzerland and France are looking to establish a unique European Rapid Response Seismic Network (ERRSN) for optimal intervention after earthquakes. In this context, and despite the difficulties that have been encountered, the scientific results gained with the L'Aquila experience underline the importance of wide deployment, and hence of coordination at the European level.

Rapid-response networks need to agree on common strategies for network operations. Decision making must be streamlined and coordinated, and based on the improved knowledge of the potential losses and existing local capacities. Partners should agree beforehand on suitable communication channels, and decide also on the need for specialization. These procedures will be defined over the next year. Different partners can cover different tasks; e.g. one specializing in very rapid response with light equipment, another in sustained efforts for month-long monitoring, and another in investigating site effects and/or monitoring building structures for engineering purposes. The project will also work to develop the tools necessary to allow optimization of the network geometry, taking into account the main cultural noise sources, the historic seismicity, the building distribution, and the land topography, and will develop and produce tutorials to increase inter-operability between the crews in the field.

The data needs to be exchanged using common protocols for data archiving (in terms of waveforms and metadata), and common database formats are needed; the NERA project has proposed the EIDA platform as the 
A)
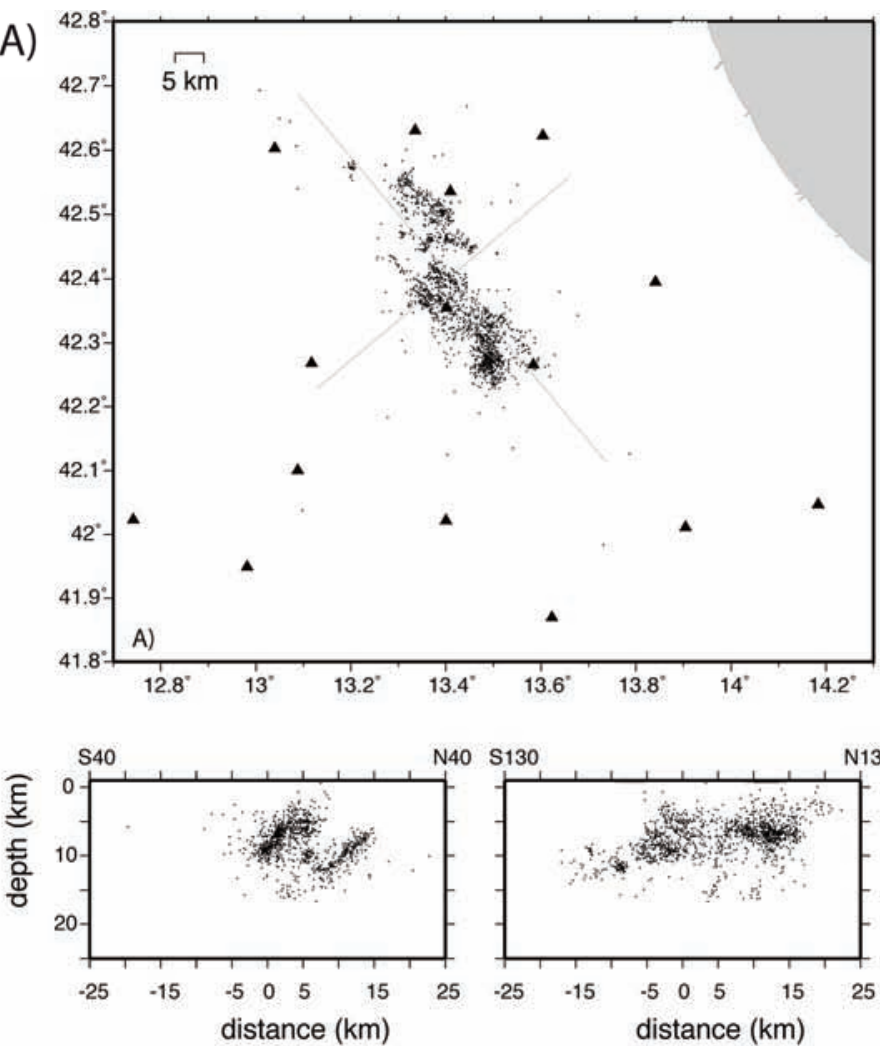

$\mathrm{N} 40 \mathrm{~S} 130$

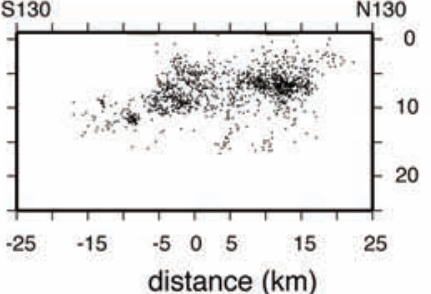

B)
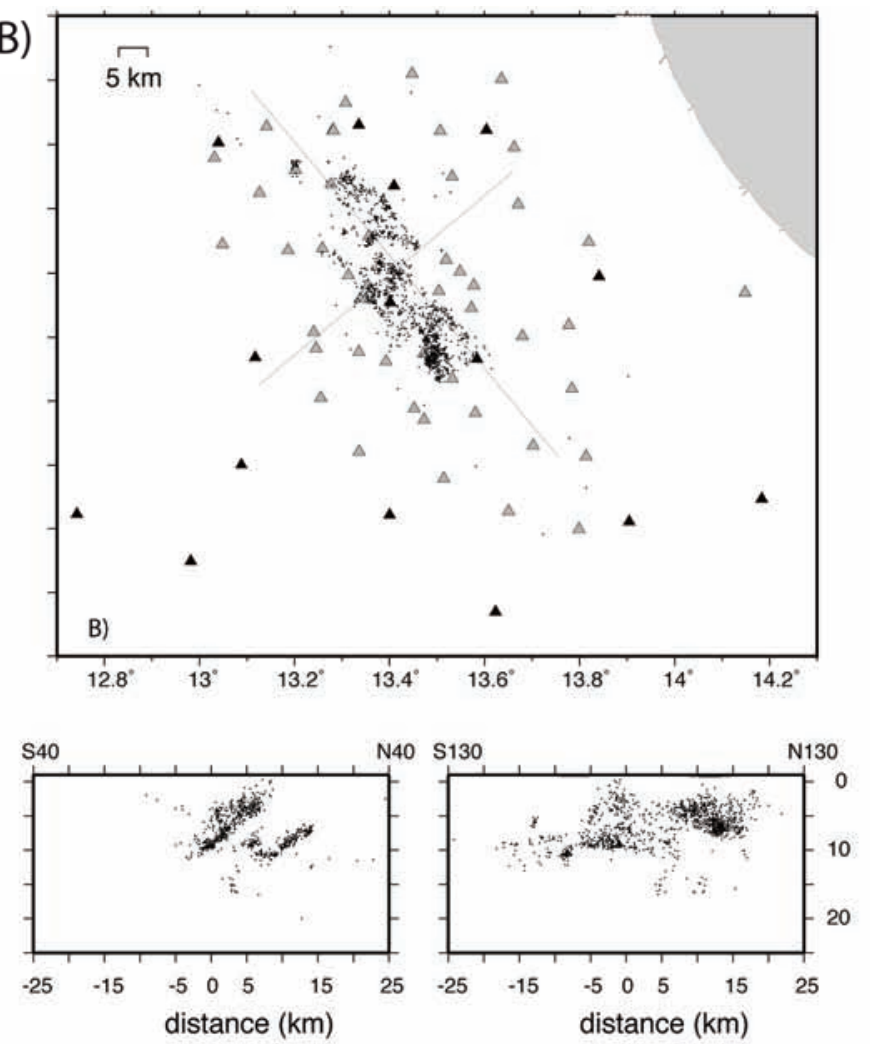

Figure 3. (A) Hypocentral locations using the permanent network (black triangles) for earthquakes with $M>1.9$ between April and June, 2009. Map above and cross-sections below. The cross sections are reported as two perpendicular grey line in the map. (B) Hypocentral locations using the permanent network (black triangles) and the emergency networks (gray triangles) for earthquakes with $M>1.9$ between April and June, 2009. Again, map above and cross-sections below. The cross sections are reported as two perpendicular grey line in the map.

A)

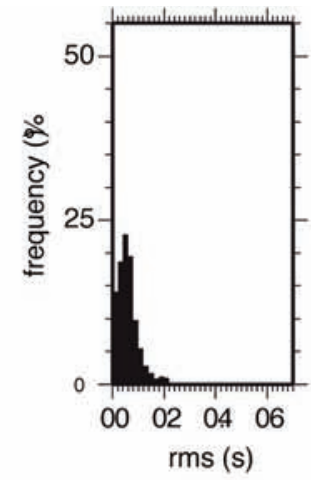

B)

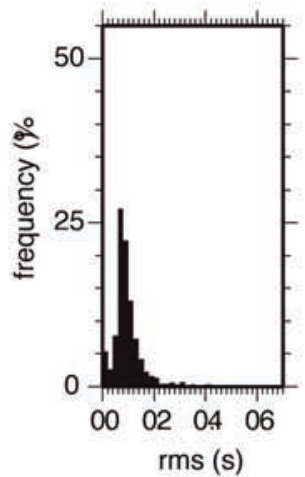

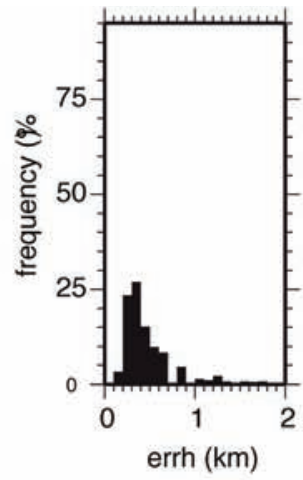

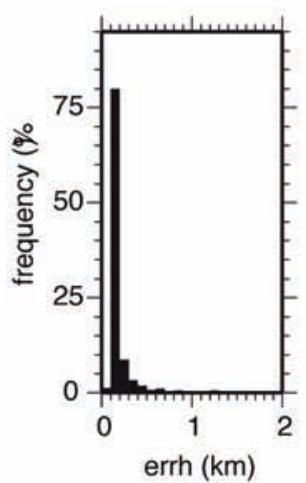

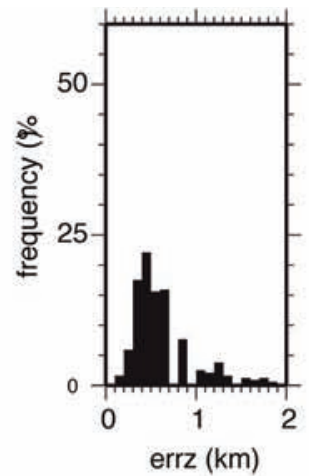
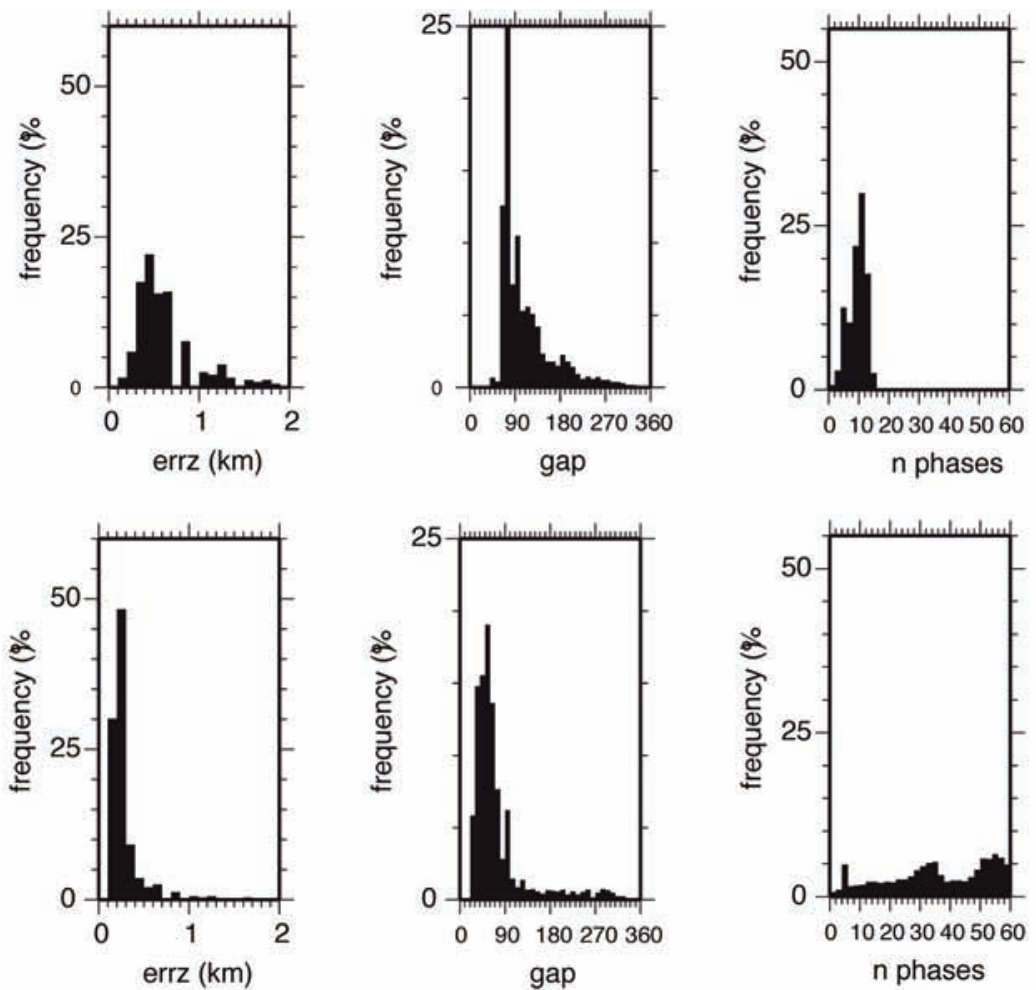

Figure 4. Location parameters for the $\mathrm{M}_{\mathrm{L}}>1.9$ earthquakes of the 2009 L'Aquila sequence obtained using: (A) data from the Italian National network; and (B) data from the Italian National network and the local networks (INGV - LGIT). 


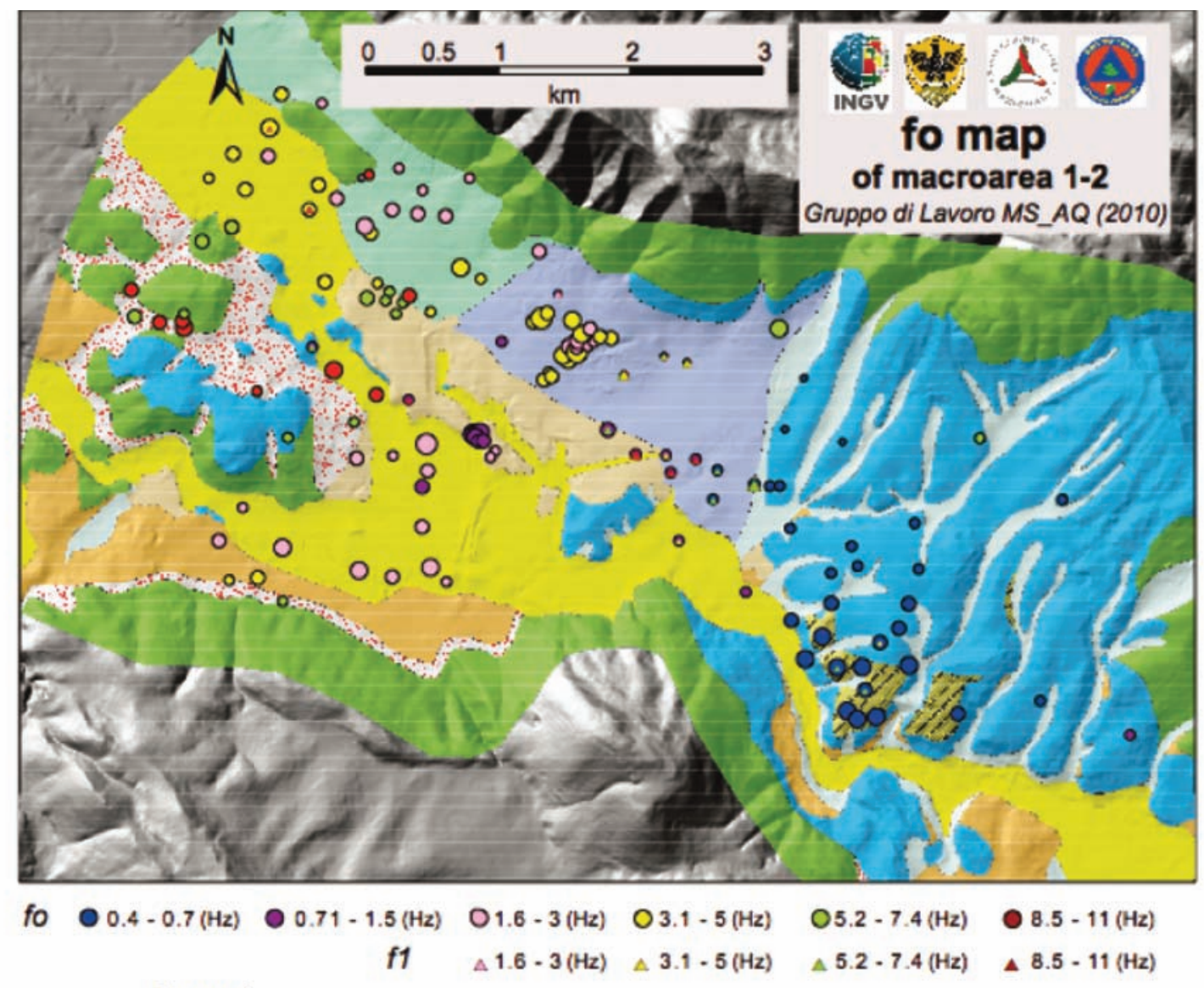

Legend
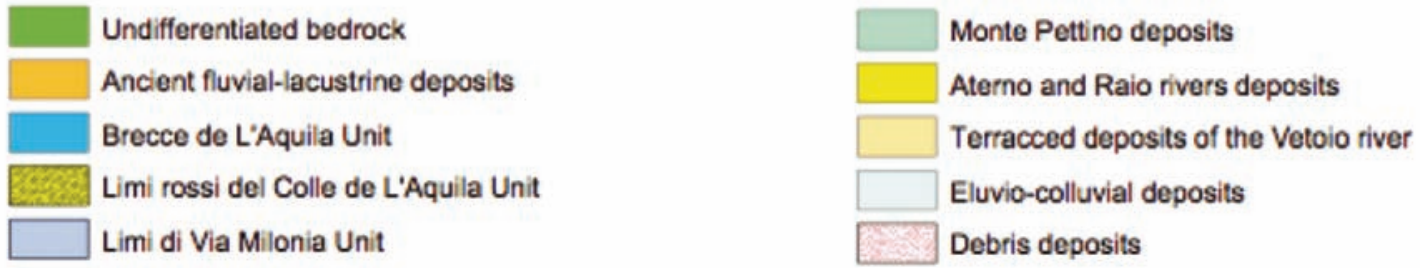

Figure 5. Map showing the fundamental frequencies (fo) and the second frequency peak (f1) extracted from the H/V ratios of the seismic noise. The values of fo and f1 are classified into six groups (circles or triangles; different colors; see legend in Figure), with the sizes of the symbols indicative of the amplification amplitude.

common archive. Hopefully, in the next few years the ERRSN will became a reality.

Acknowledgements. We are grateful to many other colleagues at the INGV and at other Institutions who contributed to the handling of the L'Aquila emergency. This study has partially benefited from funding provided by the NERA project and by funding provided by the Italian Presidenza del Consiglio dei Ministri, Dipartimento della Protezione Civile (DPC). Scientific reports funded by the DPC do not represent its official opinion and policies.

\section{References}

Amato, A. and F.M. Mele (2008). Performance of the INGV

National Seismic Network from 1997 to 2007, Annals of Geophysics, 51 (2-3), 417-431.

Ameri, G., A. Oth, M. Pilz, D. Bindi, S. Parolai, L. Luzi, M. Mucciarelli and G. Cultrera (2011). Separation of source and site effects by generalised inversion technique using the aftershock recordings of the 2009 L'Aquila earth- quake, B. Earthq. Eng., 9, 717-739; doi: 10.1007/s10518011-9270-6.

Bergamaschi, F., G. Cultrera, L. Luzi, R.M. Azzara, G. Ameri, P. Augliera, P. Bordoni, F. Cara, R. Cogliano, E. D'Alema, D. Di Giacomo, G. Di Giulio, A. Fodarella, G. Franceschina, F. Galadini, M.R. Gallipoli, S. Gori, P. Harabaglia, C. Ladina, S. Lovati, S. Marzorati, M. Massa, G. Milana, M. Mucciarelli, F. Pacor, S. Parolai, M. Picozzi, M. Pilz, S. Pucillo, R. Puglia, G. Riccio and M. Sobiesiak (2011). Evaluation of site effects in the Aterno River valley (central Italy) from aftershocks of the 2009 L'Aquila earthquake, B. Earthq. Eng., 9, 697-715; doi: 10.1007/s10518-011-9245-7.

Bordoni, P., J. Haines, G. Milana, S. Marcucci, F. Cara and G. Di Giulio (2011). Seismic response of L'Aquila downtown from comparison between $2 \mathrm{D}$ synthetics spectral ratios of SH, P-SV and Rayleigh waves and observations of the 2009 earthquake sequence, B. Earthq. Eng., 9, 761-781; doi: $10.1007 /$ s10518-011-9247-5. 
Chiarabba, C., A. Amato, M. Anselmi, P. Baccheschi, I. Bianchi, M. Cattaneo, G.P. Cecere, L. Chiaraluce, M.G. Ciaccio, P. De Gori, G. De Luca, M. Di Bona, R. Di Stefano, L. Faenza, A. Govoni, L. Improta, F.P. Lucente, A. Marchetti, L. Margheriti, F. Mele, A. Michelini, G. Monachesi, M. Moretti, M. Pastori, N. Piana Agostinetti, D. Piccinini, P. Roselli, D. Seccia and L. Valoroso (2009). The 2009 L'Aquila (central Italy) Mw 6.3 earthquake: main shock, Geophys. Res. Lett., 36, L18308; doi: 10.1029/2009GL039627.

Chiaraluce, L., C. Chiarabba, P. De Gori, R. Di Stefano, L. Improta, D. Piccinini, A. Schlagenhauf, P. Traversa, L. Valoroso and C. Voisin (2011). The 2009 L'Aquila (Central Italy) Seismic Sequence, Bollettino di Geofisica Teorica e Applicata, 52 (3); doi: 10.4430/bgta0019.

Cultrera, G., M. Mucciarelli and S. Parolai (2011). The L'Aquila earthquake - A view of site effects and building behavior from temporary networks, B. Earthq. Eng., Introduction to the Special Issue, 9, 691-695; doi: 10.1007 / s10518-011-9270-6.

D'Alema, E., S. Marzorati, M. Massa, G. Franceschina and P. Augliera (2010). The April 6, 2009, Mw 6.3, L'Aquila sequence: weak-motion and strong-motion data recorded by the RAIS temporary stations, Annals of Geophysics, 53 (2), 101-113; doi: 10.4401/ag-4565.

Di Giulio, G., S. Marzorati, F. Bergamaschi, P. Bordoni, F. Cara, E. D'Alema, C. Ladina, M. Massa and The L'Aquila Experiment Team (R.M. Azzara, R. Cogliano, G. Cultrera, A. Fodarella, L. Luzi, G. Milana, S. Pucillo, G. Riccio) (2011). Local variability of the ground shaking during the 2009 L'Aquila earthquake (April 6, 2009-Mw 6.3): the case study of Onna and Monticchio villages, B. Earthq. Eng., 9, 783-807; doi: 10.1007/s10518-011-9243-9.

Gruppo di Lavoro MS_AQ (2010). Microzonazione sismica per la ricostruzione dell'area aquilana. Abruzzo region Working group coordinated by the Italian Civil Protection, 2 vols. and 1 DVD.

Di Stefano, R., C. Chiarabba, L. Chiaraluce, M. Cocco, P. De Gori, D. Piccinini, and L. Valoroso (2011), Fault zone properties affecting the rupture evolution of the 2009 (Mw 6.1) L'Aquila earthquake (central Italy): Insights from seismic tomography, Geophys. Res. Lett., 38, L10310; doi: 10.1029/2011GL047365.

Margheriti, L., M. Anselmi, A. Antonioli, R. Azzaro, P. Baccheschi, A. Bono, B. Castello, C. Chiarabba, L. Chiaraluce, M.G. Ciaccio, G.B. Cimini, G. Colasanti, M. Colasanti, F. Criscuoli, S. D'Amico, P. De Gori, A. Delladio, M. Di Bona, R. Di Stefano, A. Frepoli, E. Giandomenico, L. Giovani, A. Govoni, L. Improta, V. Lauciani, A.G. Mandiello, C. Marcocci, S. Mazza, M. Moretti, N.M. Pagliuca, N. Piana Agostinetti, D. Piccinini, D. Seccia, F.P. Lucente, S. Pintore, L. Pizzino, P.R. Platania, M. Quintilliani, S. Rapisarda, G. Selvaggi, A. Serratore, M. Silvestri,
S. Silvestri, G. Soldati, L. Valoroso and L. Zuccarello (2010). Emergenza "L'Aquila2009": la campagna di acquisizione dati della Rete Sismica Mobile stand-alone del Centro Nazionale Terremoti, Rapporti Tecnici INGV, 151, 54 pp.; available for download at http://portale.ingv.it/portale_ingv/produzione-scientifica/rapporti-tecniciingv/archivio/copy_of_numeri-pubblicati-2010/).

Milana, G., R.M. Azzara, E. Bertrand, P. Bordoni, F. Cara, R. Cogliano, G. Cultrera, G. Di Giulio, A.M. Duval, A. Fodarella, S. Marcucci, S. Pucillo, J. Régnier and G. Riccio (2011). The contribution of seismic data in microzonation studies for downtown L'Aquila, B. Earthq. Eng., 9, 741-759; doi: 10.1007/s10518-011-9246-6.

Mucciarelli, M., M. Bianca, R. Ditommaso, M.R. Gallipoli, A. Masi, C Milkereit, S. Parolai, M. Picozzi, M. Vona (2009). Far field damage on RC buildings: the case study of Navelli during the L'Aquila (Italy) seismic sequence, B. Earthq. Eng., 9, 263-283; doi: 10.1007/s10518-010-9201-y. Picozzi, M., R. Ditommaso, S. Parolai, M. Mucciarelli, C. Milkereit, M. Sobiesiak, D. Di Giacomo, M.R. Gallipoli, M. Pilz, M. Vona and J. Zschau (2010). Real time monitoring of structures in task-force missions: the example of the Mw = 6.3 Central Italy Earthquake, April 6, 2009, Nat. Hazards, 52 (2), 253-256; doi: 10.1007/s11069-0099481-1.

Pondrelli S., S. Salimbeni, A. Morelli, G. Ekstrom, M. Olivieri and E. Boschi, Seismic moment tensors of the April 2009, L'Aquila (Central Italy), earthquake sequence, Geophys. J. Int., 180, 238-242; doi: 10.1111/j.1365-246X.2009.04418.x.

Puglia, R., R. Ditommaso, F. Pacor, M. Mucciarelli, L. Luzi and M. Bianca (2011). Frequency variation in site response over long and short time scales, as observed from strong motion data of the L'Aquila (2009) seismic sequence, B. Earthq. Eng., 9, 869-892; doi: 10.1007/s10518011-9266-2.

Scognamiglio, L., E. Tinti, A. Michelini, D. Dreger, A. Cirella, M. Cocco, S. Mazza and A. Piatanesi (2010). Fast determination of moment tensors and rupture history: application to the April 6th 2009, L'Aquila earthquake, Seismol. Res. Lett., 81 (6), 892-906; doi: 10.1785/gssrl.81.6.892.

Valoroso, L., and L'Aquila 2009 Mobile Network Working Group (2009). The 2009 L'Aquila seismic sequence (central Italy): Fault system geometry and kinematics, Eos Trans. AGU, 90 (52), Fall Meet. Suppl., Abstract U12A-04.

\footnotetext{
*Corresponding author: Lucia Margheriti, Istituto Nazionale di Geofisica e Vulcanologia,Centro Nazionale Terremoti, Rome, Italy; email: lucia.margheriti@ingv.it.

(C) 2011 by the Istituto Nazionale di Geofisica e Vulcanologia. All rights reserved.
} 